TERRY BYERS AND WESLEY IMMS

\title{
10. EVALUATING THE CHANGE IN SPACE IN A TECHNOLOGY-ENABLED PRIMARY YEARS SETTING
}

\section{INTRODUCTION}

There has been considerable attention in the literature postulating the potential effects of contemporary, technology-enabled new generation learning spaces (NGLS) on both teaching and learning (Brooks, 2011, 2012). This has, in part, been driven by the pervasive and transformative potential of ubiquitous access to and use of digital technology in the classroom (Chan et al., 2006).

Increased access to mobile technology in recent years has freed students from the restrictive nature of shared access in traditional computer laboratories (Blackmore, Bateman, O'Mara, \& Loughlin, 2011). Students now have personal 'anywhere, anytime' access to a boundless library of highly indexed information (Beichner, 2014), which in turn challenges the highly sequential style of instruction that has allowed teachers to preserve their historically authoritative role.

Personal access to technology can support more adaptive and connected learning experiences. These experiences are created by connecting teachers and students within multimodalities of teaching and learning that may have not been possible before (Bocconi, Kampylis, \& Punie, 2012; Hall-van den Elsen \& Palaskas, 2014; Swan, van'T Hooft, Kratcoski, \& Schenker, 2007). Multimodalities afford teachers the ability to orchestrate adaptive learning opportunities using a range of physical, text and visual tools, whilst connecting students with each other.

A key element is the connectivity between teachers-students and studentsstudents is established through the creation of technology-enabled NGLS. The technology-enabled spaces have ubiquitous access to digital technology through one-to-one digital devices connected through wireless infrastructure.

The affordances of a NGLS environment has the potential to revolutionize how, where and with whom students learn (Mouza \& Lavigne, 2013; Thomas \& Brown, 2011). It has the potential to support contemporary pedagogical practices that facilitate highly personalised models of student learning (Bocconi et al., 2012; Magee, 2009; Zandvliet \& Fraser, 2004). This personalised model includes learning outside the primacy of the traditional classroom forum (Mouza \& Lavigne, 2013). Together these elements intertwine to create a model of teaching and learning that can be radically different to prevailing school cultures (Mouza \& Lavigne, 2013). 
Despite this potential, many have argued that digital technology has often been imposed on traditional classroom spaces (Bautisa \& Borges, 2013; Chandler, 2009; Sawyer, 2006), which have changed little in configuration, structure and operation for the best part of a century (Burke \& Grosvenor, 2008). New technologies in these traditional spaces have a tendency to sustain and reinforce existing pedagogical practices (Fisher, 2010; Lippman, 2010; Richards, 2006).

An example of this imposition is the integration of interactive white boards (IWB) into primary or elementary year classrooms. IWB have experienced a high level of interest over the past 20 years and are now commonplace. This success has arguably stemmed in part from an ability to afford both teachers and students access to visually appealing, interactive and dynamic electronic content.

A review by Higgins, Hall, Wall, Woolner, and McCaughey (2005) raised concerns that some teachers have merely 'bolted on' a slightly more impressive display format to their existing stand-and-deliver pedagogical approach, the underlying assumption being that "technology is something that you add on to existing pedagogy, and vice versa" (Richards, 2006, p. 240). This continues and reinforces existing pedagogical practices, and works against any transformative potential of digital technologies (Hughes, Thomas, \& Scharber, 2006; Lippman, 2010; Mishra \& Koehler, 2006).

For digital technology to act as a catalyst for pedagogical transformation it must be integrated within, rather than imposed upon, a dynamic and responsive learning environment (Cleveland, 2011; Higgins, Xiao, \& Katsipataki, 2012; Lippman, 2010; Radcliffe, Wilson, Powell, \& Tibbetts, 2008). Such approaches are scarce - Bautista and Borges (2013) are critical of a virtually non-existent discourse concerning this alignment of the physical attributes of the classroom to support the intensive integration of digital devices. Such silence arguably stems from a dearth of hard evidence concerning the impact of technology on teaching and learning within NGLS (Blackmore et al., 2011; Brooks, 2011; Painter et al., 2013). Little is known about how and why the physical attributes of these technology-enabled and contemporary spaces affect the nuances of the teaching and learning processes (Chandler, 2009; Upitis, 2009).

This chapter attempts to partly fill this void in our knowledge. It reports an empirical study that explored how interaction between space and digital technology affected teaching and learning in two primary or elementary years settings. A synthesised quasi-experimental and Single Subject Research Design (SSRD) approach compared student perceptions of the effectiveness of technology, their learning experiences and levels of engagement within a traditional and a NGLS classroom space.

It replicates the data analysis techniques applied in previous studies (Byers, Imms, \& Hartnell-Young, 2014; Byers \& Imms, 2014) that identified statistically significant changes in student perceptions in each of the spaces. This study supports findings from these earlier studies, which argued the physical learning environment acted as a mechanism to either hinder or support pedagogical practices within 
technology-enhanced environments. In addition this study provides further evidence supporting the credibility of this unique methodological approach, arguing it offers the capacity to generate much needed robust empirical data on the evaluation of physical learning spaces.

\section{LITERATURE REVIEW}

\section{The Transformative Potential of Digital Technology in the Classroom}

In Australia much attention has been placed on the integration of technology in senior secondary classrooms, initially under that country's federally funded program called the Digital Education Revolution (DER) and more recently through 1-to-1 or Bring Your Own Device (BYOD) programs. Collectively these programs have seen the swift proliferation of digital devices into the secondary years of schooling.

Their aim is to create technology-enabled learning environments by facilitating ubiquitous student and teacher access to and connection through technology. Buchanan (2011) has described this proliferation as the culmination of the digital turn that has swept through education over the past two decades.

A number of researchers have postulated that ubiquitous teacher and student access to technology has the potential to be a mechanism to facilitate and drive innovative teaching and creative learning (e.g., Bautista \& Borges, 2013; Richards, 2006; Rosen \& Beck-Hill, 2012). The inherent affordances of digital technology provide teachers with avenues to accommodate a wider range of learning modalities (Bautista \& Borges, 2013; Rosen \& Beck-Hill, 2012). The modalities can extend beyond the traditional uni-modal approach, which draws on a model of instruction that predominately operates at the transmission end of the learning continuum, to better support a dynamic suite of multimodal pedagogical approaches (Hermans, Tondeur, van Braak, \& Valcke, 2008; Hildebrand, 1999; Upitis, 2004; Zucker, 2007). This suite enables teachers to align the right digital tool/s to support the most pedagogically appropriate approach/es to facilitate the desired learning intent and/or outcomes.

This alignment between the capacities of digital technology can foster a new culture of student-centred learning (Bautista \& Borges, 2013; Hermans et al., 2008). Here the students are at the heart of the process and participating in ways that were not possible before (Bautista \& Borges, 2013). Unlike the hierarchical and consistent uni-modal approach, there is the ability to transition to more flexible, personalised and adaptive approaches (Jessop, Gubby, \& Smith, 2012). With greater flexibility comes the ability to accommodate a wider variety of more collaborative learning modalities (Blin \& Munro, 2008). In this more student-centric approach, learning is more authentic, responsive and conceived as a social process (Blin \& Munro, 2008).

This social-constructive learning environment supports students in learning new information and behaviours from one another, in addition to their teacher (Lin, Wang, \& Lin, 2012). This requires a shift in the traditional role as the sole source of new knowledge. Instead, students access the collective expertise of a wider audience. 
Student can learn from their peers and others, inside or outside the confines of their classroom or school. These informal peer-to-peer or expert-to-novice interactions lead to learners learning from each other (Bautista \& Borges, 2013).

\section{Integration of Digital Technology into the Primary Year's Space}

In Australia the primary or elementary years of schooling have not received the same level of systemic funding as secondary years to provide improved student access to technology. This lack of systemic funding has not limited the broad integration of or enthusiasm for digital technology into primary or elementary years classrooms.

Many schools, and their parental communities, have funded their own purchase of mobile digital devices for use in the classroom. The enthusiasm behind this selffunded integration is unlikely to diminish in the near future. This integration is driven by a general belief in the wider community that digital technology can offer new teaching and learning opportunities and modalities.

This enthusiasm is evident in the somewhat fervent adoption of tablet and iPad devices (Higgins et al., 2012). Unlike in one-to-one or BYOD programs, these portable and touch-based devices are usually shared between students and/or classes. Compared to laptops, these devices are more suited to the learning needs and the 'technologic' capacity of primary year students. Their size, use of versatile apps and touch-based nature enable students to easily manipulate and interact with learning objects to make learning active and participatory (Hur \& Oh, 2012).

This style of touch-based learning has been established in the primary years for quite some time through the use of interactive white boards (IWB).

IWBs have received widespread systemic endorsement and funding (Condie \& Munro, 2007; Higgins, Beauchamp, \& Miller, 2007; Wood \& Ashfield, 2008). This has enabled IWBs to become the most common 'technology' found in primary years learning spaces due to their ability to facilitate whole-class pedagogy (Higgins et al., 2007). Higgins et al. (2005) and (2007) studies found that their use correlated to a positive impact on student engagement and attention and served as a catalyst for teacher pedagogical change. However, McCarter and Woolner (2011) are of the view that this shift to a whole class, teacher-centric pedagogy, supported by an IWB, does suggest that the arrangement of the classroom is now being led by technology rather than pedagogy.

\section{The Imposition of Digital Technology as a Trojan Horse}

If indeed there is a 'digital turn' in process as argued by Buchanan (2011), this may explain the perception that there is a growing dependence in primary or elementary schools on digital technology within everyday teaching and learning (Prieto, Dlab, Gutiérrez, Abdulwahed, \& Balid, 2011).

Certainly research is beginning to claim that technology can be a catalyst that will transform teaching and student learning experiences and ultimately improve learning 
outcomes (Donovan, Green, \& Hartley, 2010; Matzen \& Edmunds, 2007). This is largely a technocentric belief that integration of technology is a 'Trojan horse', a way of surreptitiously eliciting paradigmatic change in teaching and learning (Harris, 2005; Hermans et al., 2008; Rosen \& Beck-Hill, 2012; Watson, 2006). This rather ambitious claim requires evidence to prove its credibility.

What is less conjectural is that the imposition of technology into unchanged spaces typically leads to technology operating within unchanged pedagogical modes (Bautista \& Borges, 2013; Blin \& Munro, 2008; Lippman, 2010; Richards, 2006). For Hughes (2005) the use of "technology serves merely as a different means to the same instructional end" (p. 1617). In essence this replication of already functioning instructional methods and learning processes changes the medium or mechanism used to achieve an established process (Hughes et al., 2006). It is argued that this peripheral teacher use of technology is a result of the lack of knowledge, beliefs and requisite support frameworks (Rosen \& Beck-Hill, 2012).

For teachers to either amplify existing practices or innovate through exploiting the transformative potential of technology, there is a need to examine the complexity of factors and the confounding variables that influence both teaching and learning (Donovan et al., 2010; Ross, Morrison, \& Lowther, 2010).

Here it is clear that the adoption and use of technology is dependent on a teacher's set of beliefs, ingrained knowledge and teaching ability (e.g., Bingimlas, 2009; Weston \& Bain, 2010). Cuban (2001) and Bebell and Kay (2010) have described teachers as gatekeepers to their classroom and therefore student technology usage.

Only when a teacher's pedagogical practice is at the heart of any intervention or reform, will it be possible to observe the consequential flow on to enhancing student engagement and learning outcomes (Ross et al., 2010).

\section{The Built Pedagogical Contract Created by the Imposition of Technology}

The integration of IWB and other technologies into existing structures has been symbolic of this top-down imposition of technology. Too often the integration of technology has been a mere add-on to existing structures (Richards, 2006). Fisher (2010) argued that any lack of profound change was due to the misalignment of affordances of technology and the supposed common traditional didactic instructional setting.

This misalignment steams from a deep spatial silence around the hidden effects of the physical learning environment, he claims. It is the influence of these surreptitious effects that has a significant role in preventing the effective implementation of technology and to support multimodal pedagogical practices (Fisher, 2004; Lippman, 2010).

The integration of singular-focal point technologies, such as IWB, has typified this lack of alignment. Like the blackboard and whiteboard that preceded it, the IWB's front and central location dominates the classroom space. This front, central focal point continues what Reynard (2009) has described as the fireplace syndrome. 
The organisation of furniture and pedagogy around this focal point, has established a highly consistent pedagogical script (Reynard, 2009; Wilks, 2009).

This script and its relationship to the physical classroom environment is encapsulated by the concept of built pedagogy developed by Monahan (2002). Built pedagogy is defined as the ability of the cultural, psychological and behavioural characteristics of the physical space to shape teacher practice and student learning (Monahan, 2002). As the traditional teacher-centric classroom has remained largely unchanged, so has its built pedagogy. This lack of change is a key factor in the highly consistent uni-modal pedagogical script between teachers and students (Wilks, 2009).

This script has been so consistent that it has established an entrenched 'built pedagogical contract' that has set the tone for what is perceived to be quality teaching and learning (Hildebrand, 1999; Wilks, 2009). This hegemonic pedagogical practice has set a clear and dominating educational equation between student(s) and teacher(s) (Hildebrand, 1999). In this equation the teachers are obligated to be the transmitters knowledge, while students are the passive receivers and consumers of this knowledge (Cleveland, 2009; Reynard, 2009). As long as this equation is unchallenged then the potential of different or innovative practices, such as the integration of ubiquitous access to technology, will never be maximized (Hildebrand, 1999; Reynard, 2009).

If the innovative potential of digital technology in education is to be realized, then the hegemonic or 'natural' teacher practices must be challenged (Hildebrand, 1999). These inherent practices are of central importance to the concept of what teachers, and to a lesser extent students, constitutes quality teaching and learning (Johnston, Ottenbacher, \& Reichardt, 1995; Hildebrand, 1999) has seen that innovative teaching practices, and therefore attempts of paradigmatic reform, have been largely unsuccessful as they explicitly and implicitly contest the underlying metaphors of this hegemonic practice. By challenging the status quo this results in resistance by teachers and/or students, as they are uncomfortable with transgressions in their perception of the norms of the teaching and learning contract (Hildebrand, 1999). Fullan, Hill, and Crevola (2007) have described how this resistance is responsible for the entrenched and perpetuating resident pedagogical culture within schools and the classroom (Fullan et al., 2007). This powerful culture innately resists change to maintain the status quo (Fullan et al., 2007; Hughes, 2010; Jacklin, 2000; McGregor, 2004; Upitis, 2004; Wilks, 2009).

What is required is evidence that transforming the spatial arrangements of a classroom has a demonstrable effect on effective use of technologies. This may or may not be facilitated by changed pedagogic practices. It may or may not be caused by students being freed from some supposed student/teacher contract created by didactic oriented classrooms. What is of interest, and thus the focus of this study, is the simple question - if you move a primary or elementary teacher and his/her students from a didactic-oriented classroom into a technology-enabled NGLS, is there a measurable change in their effective use of technologies? 
THE STUDY

\section{The Spaces}

The study took place within two buildings. The first housed the students' General Learning Area (GLA) homeroom constructed between 1950 and 1960. The four classrooms in this building utilised for the baseline and withdrawal periods would be considered 'traditional' in layout. Individual student desks were set in a combination of small rows ( 2 to 3 desks) or clustered in small groups, facing a teaching position at the centre-front of the room. This space was delineated by the teacher desk and IWB. The integration of the IWB and wireless infrastructure were recent additions to these spaces. This enabled the teacher and shared student Tablet PCs to connect to the school's network and Internet.

The second building was a recently refurbished building that housed the library, which had within its structure a 'Place of Discovery' or POD.

This POD utilised NGLS principles designed, implemented and evaluated in the Byers et al. (2014) and Byers and Imms (2014) studies. NGLS are complete and interactive $360^{\circ}$ learning environments created through a 'polycentric layout' (Figure 1). A polycentric layout is created by multiple teacher and student focal points. The aim was to remove or de-emphasise Reynold's (2009) 'fireplace' at the front of the room. This multiple focal point layout was created using TOWs large TV's on Walls/Wheels (Lippman, 2013; Miller-Cochran \& Gierdowski, 2013), 'writeable walls' and multiple teacher data projector inputs. The notion of a polycentric layout was inspired by success of their implementation in the North Carolina State University's Student-Centred Activities for Large Enrolment Undergraduate Program (SCALE-UP), Massachusetts Institute of Technology's Technology Enabled Active Learning (TEAL) project; and University of Minnesota's Active Learning Classrooms (ALC) projects.

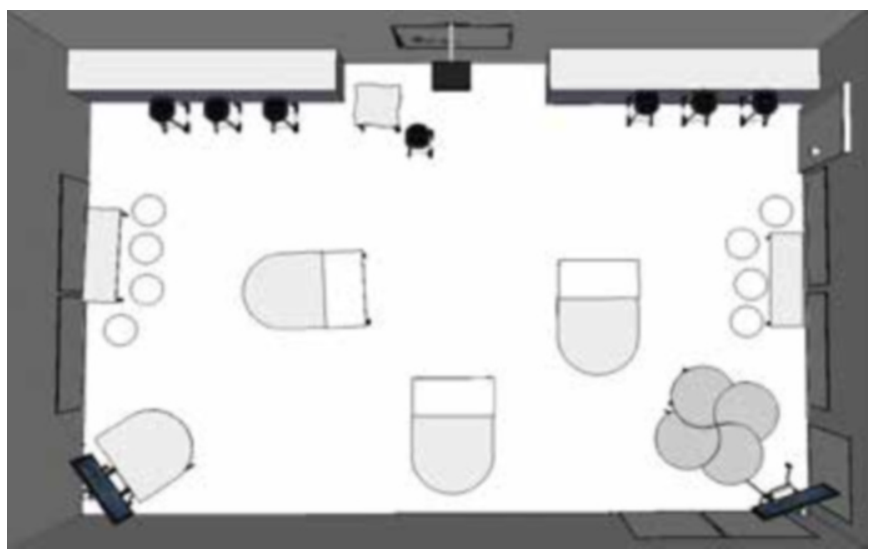

Figure 1. Polycentric layout of a NGLS 
In an improvement on the original NGLS design, the flexibility of the space was enhanced through manipulation of desk heights. The combination of 'floor', 'sitting' and 'standing' desk heights delineated the visual perspective of the space. The aim was to create both traditional and non-traditional seating option, support student and teacher movement and allow students to work with greater comfort. Collectively the aim was to afford the teacher the ability to create different spatial configurations to match the pedagogical intent of the lesson or activity (Brooks, 2012; Byers et al., 2014). (The traditional 'one seat per student' infrastructure was also ignored, to de-clutter the space and increase the opportunity for student mobility.)

\section{Research Design}

To advance contemporary learning space theory, there is a need to move beyond postulation and establish empirically-based causal links between how these spaces translate into improvements in teaching and learning. However, ethical considerations surrounding research in schooling environments rarely support the requisites of a randomised experimental study (Clegg, 2005; Shadish \& Cook, 1999). As a consequence, a synthesised quasi-experimental and single subject research design (SSRD) were employed due to its extensive and well-established application in non-randomised intervention studies in the applied and clinical health sciences (Harris et al., 2006; Johnston et al., 1995). This approach was previously successfully implemented by Byers and Imms (2014) and Byers et al. (2014) studies in a similar educational context.

Unlike randomised experimental studies, this synthesised approach placed greater emphasis on the design of the study, rather than statistics alone, to facilitate causal inference (Shadish \& Cook, 1999). A key facet of this design was the control of the spuriousness effect/s of confounding variables, to then isolate and measure the effect of a single intervention (Coryn, Schröter, \& Hanssen, 2009; Robson, 2011). Rassafiani and Sahaf (2010) and Horner, Swaminathan, and George (2012) have argued that this control improves both within-subject variability and internal validity. As a consequence, these improvements enhanced the rigour and reliability around the claimed causality between the intervention and desired outcomes (Harris et al., 2006; Mitchell \& Jolley, 2012; West \& Thoemmes, 2010).

The research design of this study sought to control all factors (subject, class construction, assessment and the teacher), except the 'intervention'. The intervention was the shift of each of the classes from their home room GLA (traditional, general learning area) to the NGLS. The research question for the study was to determine if changing the learning space had any effect on students' perceptions of their digital device, learning experiences and levels of engagement in their 'Integrated Studies' subject (English, Humanities and Science through a project-based approach). This question was addressed using a SSRD, which systematically evaluated three research sub-questions (dependent variables): 
- What is the effect, if any, of the NGLS on students' perceived value of their digital device as a learning tool?

- What is the effect, if any, of NGLS on student learning experiences?

- What is the effect, if any, of NGLS on student engagement?

A SSRD withdrawal $\mathrm{ABA}^{1}$ design determined the effect of the intervention the change in learning space (independent variable) - on students' perceived value of their digital device, learning experiences and levels of engagement (dependent variables). The aim of the withdrawal design was to establish functional relationship between the manipulation of the intervention and the subsequent effect on the dependent variable/s (Horner et al., 2005). Byiers, Reichle, and Symons (2012) and Kinugasa, Cerin, and Hooper (2004) argued that withdrawal studies had a higher degree of experimental and internal validity control than other SSRD approaches. This design enhanced rigour and reliability around the claimed causality between the intervention and changes in the dependent variables.

\section{Methods}

The research questions were addressed through an anonymous, repeated measures student attitudinal survey. The survey used three baseline, intervention and withdrawal collection points across three terms. The repeated measures Linking Pedagogy, Technology and Space (LPTS) consisted of 10 items assigned to 3 domains. The LPTS instrument addressed the three research questions - the effect of the learning spaces on students' perceptions of technology (Domain A), their learning experiences (Domain B) and engagement (Domain C). Table 1 shows descriptions and a sample item for each LPTS domain. The items were adapted from elements of the Tamim, Lowerison, Schmid, Bernard, and Abrami (2011) longitudinal study; 'Motivated Strategies for Learning Questionnaire' (MSLQ) (Pintrich \& de Groot, 1990); and the earlier Byers et al. (2014) study.

Post-hoc reliability analysis through the calculation of Cronbach's Alpha sought to determine the internal consistency of the survey instrument. Cronbach's Alpha for the summative score for each class in each of the domains was calculated based on the suggestions of Gliem and Gliem (2003). The application of this approach resulted in initial Cronbach's Alpha's of 0.70 (Domain A), 0.79 (Domain B) and 0.71 (Domain C) respectively. These values indicate an acceptable level of reliability for the purposes of this study (Gliem \& Gliem, 2003).

\section{Sampling}

The study's sample was drawn from four primary Year 4 classes. The core curriculum of each class (English, Mathematics, Integrated Studies, Humanities, etc.) was taught by the same teacher. This curriculum was delivered in the same GLA, to classes that 
T. BYERS \& W. IMMS

Table 1. Descriptive information for the LPTS survey digital technology questions

\begin{tabular}{|c|c|c|}
\hline LPTS scale & Scale description & Sample item \\
\hline $\begin{array}{l}\text { Perception of Digital } \\
\text { Technology } \\
\text { (Domain A) }\end{array}$ & $\begin{array}{l}\text { To determine from a student perspective if } \\
\text { the use of digital technology is a learning } \\
\text { tool that aides and has any positive effect } \\
\text { on their learning }\end{array}$ & $\begin{array}{l}\text { Digital Technology has } \\
\text { had a positive influence } \\
\text { on my learning }\end{array}$ \\
\hline $\begin{array}{l}\text { Learning } \\
\text { Experiences } \\
\text { (Domain B) }\end{array}$ & $\begin{array}{l}\text { The extent to which teachers employ } \\
\text { those pedagogies that are associated } \\
\text { with student-centred learning (i.e., active } \\
\text { learning; collaborative/group interaction } \\
\text { and learning; independent creativity and } \\
\text { personalisation) }\end{array}$ & $\begin{array}{l}\text { My Teacher/s adjust } \\
\text { their pace of instruction } \\
\text { to respond to students' } \\
\text { levels of understanding }\end{array}$ \\
\hline $\begin{array}{l}\text { Engagement } \\
\text { (Domain C) }\end{array}$ & $\begin{array}{l}\text { The extent to which students assess their } \\
\text { cognitive and emotional engagement in the } \\
\text { context of particular subject/s }\end{array}$ & $\begin{array}{l}\text { This space has allowed } \\
\text { me to be in control my } \\
\text { own learning }\end{array}$ \\
\hline
\end{tabular}

would be best described as 'mixed-ability'. The students within each class were comprised of the full range of cognitive ability.

The sample size $(n=94)$ was adequate for the desired statistical power $(0.8)$. This sample represented a very high participation rate (95.1\%) of the students across the year-level cohort. A priori power analysis for the study's sample size, the probability level of $(p=0.05)$ and estimated Cohen's $d$ effect size $(d=0.6)$ meet the requirement of the desired statistical power (Faul, Erdfelder, Lang, \& Buchner, 2007). This Cohen's effect size was approximated on the basis of the lower effect sizes calculated during the Byers and Imms (2014) and Byers et al. (2014) studies, which employed a similar survey instrument and methodology. Collectively the participation rate and a priori power analysis meant that the three measures in the baseline, intervention and withdrawal phases were well within the parameters set by Vickers (2003) to ensure the desired statistical power was achieved.

\section{Data Collection}

To ensure the a priori statistical power was achieved, the maintenance of a high retention rate was essential. This required the implementation of strategies to deal with missing data from the anonymous repeated measures. Throughout the study a high retention (96.7\%) rate was achieved. It was initially assumed that any missing data was classified as Missing Completely at Random (MCAR), due to random factors such as student illness or appointments at data collection times. This assumption was verified by Little's MCAR test that resulted in a score greater than $0.05(0.88)$. This result enabled a 'missingness' approach to produce a complete data set. 
To produce a complete data set the Maximum Likelihood Estimation (ML) approach was employed. The work of Peugh and Enders (2004) has suggested that unlike mean substitution and linear regression, the ML approach would not artificially truncate the variance and covariance around the mean. This truncation would unduly bias the visual analysis process by decreasing the $95 \%$ confidence intervals (CI's) (Peugh \& Enders, 2004). The effect of decreased confidence intervals would increase the likelihood of Type 1 errors. The ML approach produced a complete data set with the same Little's MCAR coefficient as the initial data collection.

\section{DATA ANALYSIS AND DISCUSSION}

The study's a priori statistical power and high participation and retention rates, coupled with the posthoc reliability calculated through Cronbach's Alpha, supported each of the classes being summed and treated as one subject or unit. Even though this was at odds with the argument made by Perone (1999) that "averaging data over many subject can hide a multitude of sins" (p. 112). Due to the large sample size, ethical considerations around an emic research and resulting anonymity of student survey, each class served as their own control and unit of analysis.

The data from the student survey was analysed through a combination of visual analysis and inferential analysis. The visual analysis of class means, with $95 \% \mathrm{Cl}$ 's, presented a succinct mechanism to identify inter- and intra-intervention trends (Casey et al., 2012). The visual analysis process employed the simultaneous assessment of level, trend and variability within and across the NGLS and withdrawal interventions (Horner et al., 2012). Bobrovitz and Ottenbacher (1998) have claimed that this process is equitable to earlier $t$-test calculations. The application of confidence intervals as per the research of Baguley (2009), provided a superior approach to single point analysis, as it indicated the plausible range of values that the 'true' effect might take.

Exemplars of the application of this criterion are outlined in Figure 2. Panel A provides an example of a scenario that fulfilled requirements for a statistically significant difference. The non-overlapping CIs between the intervention and withdrawal phases demonstrated an immediate and stable (low variance) change in the mean after the withdrawal compared to relatively stable measures (both in mean and low variance) during the intervention phase. Panel B indicates an instance in which the visual analysis criteria was not met. Panel B shows an example of high variances and unstable trends (in both the intervention and withdrawal phases) and overlapping CIs with means. Collectively this may suggest the influence of confounding or external variable/s, outside the control of the research design.

To mitigate the 'subjective' nature of visual analysis and prevent Type 1 errors, Beeson and Robey (2006) and Kromrey and Foster-Johnson (1996) suggested that quantitative analysis through Cohen's $d$ effect size was applicable. The work of Beeson and Robey (2006) suggested that effect size calculations circumvent the 
T. BYERS \& W. IMMS

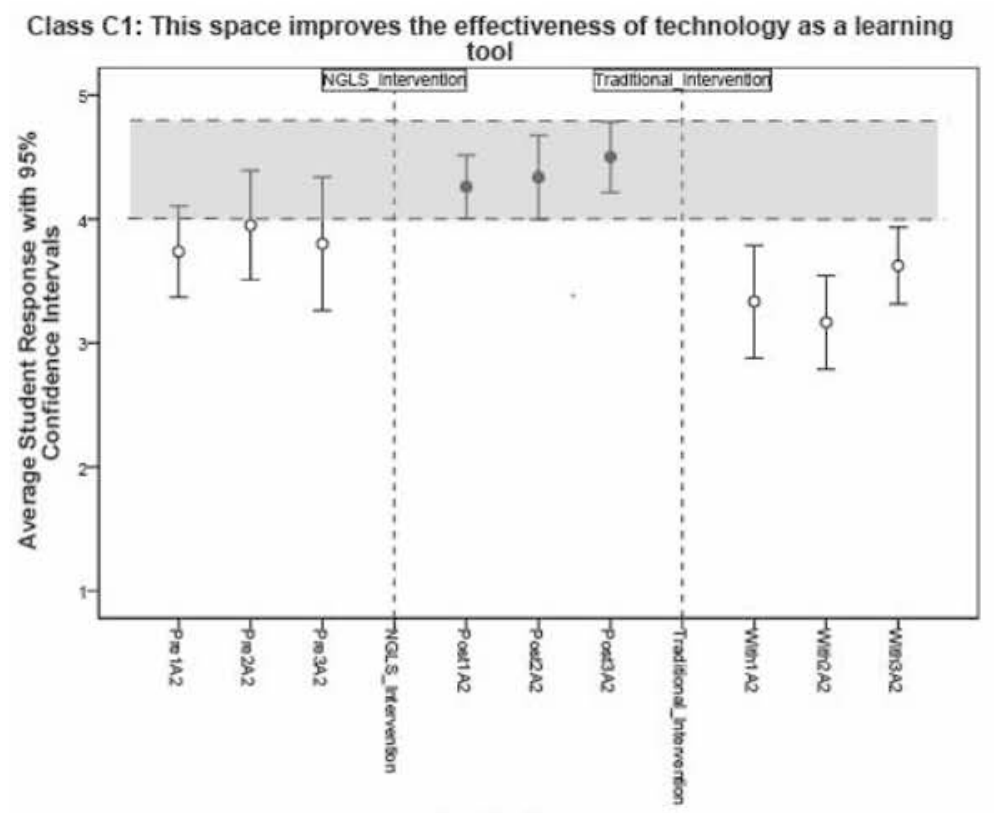

Question A2

Class C1: In this space I use technology more than traditional paper

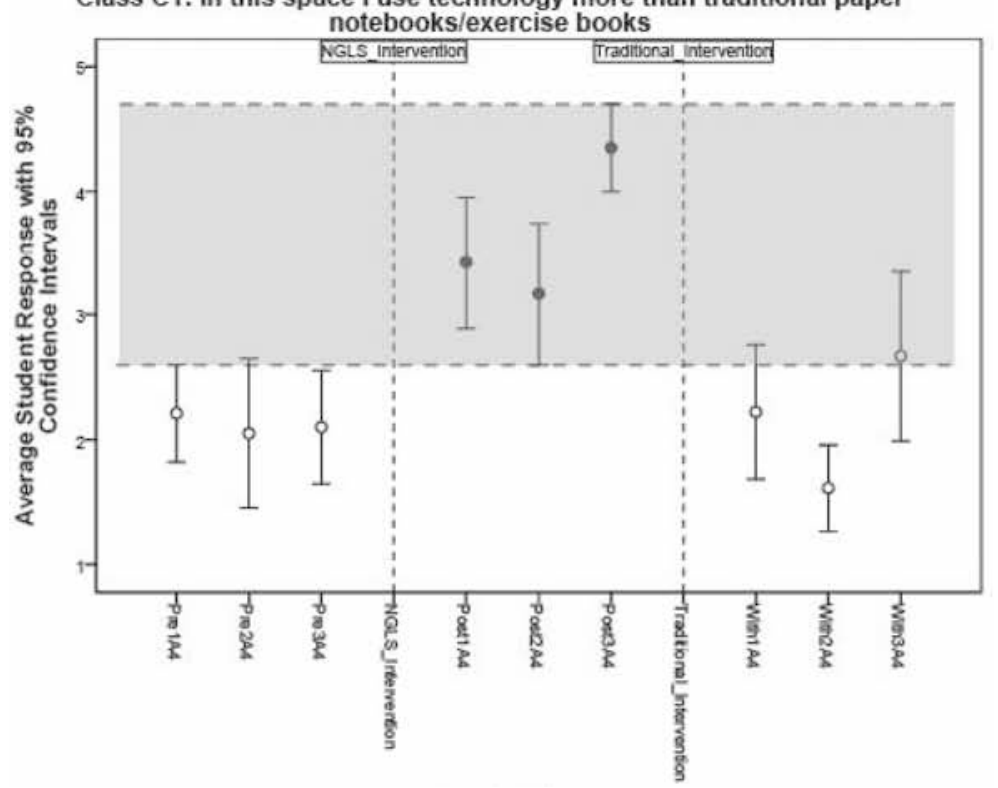

Figure 2. Visual analysis through summative means, with 95\% confidence intervals, demonstrating statistically significant (Panel A) and non-significant (Panel B) differences 
distribution issues of auto correlated (as the case of this study), which would be associated with traditional inferential statistics. The thresholds suggested by Cohen (1998) were employed to categorise the degree of the effect size.

The criterion used to determine statistically significant effects were adopted from the Byers et al. (2014) and Byers and Imms (2014) studies. A statistically significant effect required a combination of 'non-overlapping' (NO) confidence intervals (taking into account trend and variability) from the visual analysis and a large effect size $(d \geq 0.8)$. The Byers et al. (2014) and Byers and Imms (2014) studies found that an effect size within the large $(0.8 \leq d<1.3)$ range or higher, generally correlated to statistically significant differences observed through the visual analysis process.

This would suggest that statistically significant difference identified through visual analysis is corroborated by an improvement approaching one standard deviation when compared against the baseline/withdrawal data (Jenson, Clark, Kircher, \& Kristjansson, 2007).

\section{Effect of the Formal Learning Space on Student Attitudes to Digital Technology}

Within this ABA design, the shift from the NGLS (intervention) to the traditional classroom (baseline) resulted in a statistically significant difference in nine out of the sixteen questions (Table 2). All four classes returned a statistically significant difference, supported by large effect sizes $(d \geq 0.8)$ and corroborated through visual analysis, for the questions pertaining to the 'positive influence' $\left(\mathrm{A}^{1}\right)$ and 'effectiveness' $\left(\mathrm{A}^{2}\right)$ of technology. Of note, the effect sizes for the responses to the effectiveness of technology were greater than one, which indicates an overall change in excess of one standard deviation. This would suggest that layout and elements of the NGLS had a significant effect on how teachers incorporated the use of technology within their practice. This then had a corresponding effect on the way students' utilised technology as a learning tool. The correlation between the positive influence and effectiveness responses in this study appeared to provide

Table 2. Summary of the changes in student perception of the effectiveness, relevance and usage of ICT in the mode 3 space compared to mode 1 (withdrawal)

\begin{tabular}{lcccccccc}
\hline Class & $\begin{array}{c}\text { Positive influence } \\
\left(A^{1}\right)\end{array}$ & \multicolumn{2}{c}{$\begin{array}{c}\text { Effectiveness } \\
\left(A^{2}\right)\end{array}$} & \multicolumn{2}{c}{$\begin{array}{c}\text { Distraction } \\
\left(A^{3}\right)\end{array}$} & $\begin{array}{c}\text { Usage compared to } \\
\text { notebooks }\left(A^{4}\right)\end{array}$ \\
\cline { 2 - 9 } & Visual & Cohend & Visual & Cohen d & Visual & Cohen d & Visual & Cohen d \\
\hline C1 & $N O^{a}$ & 0.924 & NO & 1.205 & $O^{b}$ & 0.298 & $O$ & 1.376 \\
C2 & $N O$ & 0.867 & $N O$ & 1.027 & $O$ & 0.045 & $O$ & 0.459 \\
C3 & $N O$ & 0.855 & NO & 1.589 & $O$ & 0.354 & NO & 2.219 \\
C4 & $N O$ & 0.944 & NO & 1.027 & $O$ & 0.049 & $O$ & 0.752 \\
\hline
\end{tabular}

Note. ${ }^{a}$ Non-Overlapping confidence intervals. ${ }^{b}$ Overlapping confidence intervals. 
initial evidence to support the potential of the alignment between affordances of the physical space and technology.

The arrangement of the classroom layout appeared to have little effect on the level of student distraction attributed to their use of technology $\left(\mathrm{A}^{3}\right)$. There is research that has suggested that students are distracted by the availability of technology (e.g., Fried, 2008). In this study, students generally responded between 'disagree' to 'unsure' to their perceived level of distraction brought about by access to technology. However, the thought that a more engaging and dynamic space, as opposed to a static and teacher-centric space, would have had a more significant effect on reducing student distraction was not evident in this study.

\section{Effect of the Formal Learning Space on Student Learning Experiences}

The shift from the NGLS to the traditional classroom resulted in a statistically significant difference in six out of the sixteen questions (Table 3). All four classes returned non-statistically significant differences in their teacher's practice $\left(\mathrm{B}^{1}\right.$ and $\mathrm{B}^{2}$ ). The students did indicate that there was some 'improvement' in their teacher's practice $\left(\mathrm{B}^{1}\right)$ in the NGLS compared to their homeroom.

This improvement was approximately equivalent to a 'medium' effect. Classes $\mathrm{C} 2, \mathrm{C} 3$ and $\mathrm{C} 4$ responded in a similar fashion to the 'personalisation of instruction' $\left(\mathrm{B}^{2}\right)$ question. However, Class $\mathrm{C} 1$ responded differently, recording a 'large' effect size $(d=0.910)$. However, the variability and trend of the withdrawal period resulted in an overlapping confidence interval. As a consequence, due to the discrepancy between the visual analysis and effect size calculation, this did not meet the criteria for a statistically significant change.

The change from a NGLS to a traditional classroom did result in a statistically significant effect on student learning experiences. For the questions pertaining to increased 'interactivity' $\left(\mathrm{B}^{3}\right)$ and 'collaboration' $\left(\mathrm{B}^{4}\right)$ between students and teachers, three classes $(\mathrm{C} 1, \mathrm{C} 2$ and $\mathrm{C} 3)$ returned statistically significant improvement. The correlation between interactivity and collaboration would suggest that these classes were exposed to greater instances of working with their peers through different

Table 3. Summary of the changes in student perception of changes in teachers' practice and student collaboration in the mode 3 space compared to mode 1 (withdrawal)

\begin{tabular}{lcccccccc}
\hline Class & \multicolumn{2}{c}{$\begin{array}{c}\text { Improvement in } \\
\text { practice }\left(B^{1}\right)\end{array}$} & \multicolumn{2}{c}{$\begin{array}{c}\text { Personalisation of } \\
\text { instruction }\left(B^{2}\right)\end{array}$} & \multicolumn{2}{c}{$\begin{array}{c}\text { Increased } \\
\text { interactivity }\left(B^{3}\right)\end{array}$} & \multicolumn{2}{c}{$\begin{array}{c}\text { Incidence of } \\
\text { collaboration }\left(B^{4}\right)\end{array}$} \\
\cline { 2 - 9 } & Visual & Cohend & Visual & Cohend & Visual & Cohen d & Visual & Cohen $d$ \\
\hline C1 & $O$ & 0.643 & $O$ & 0.910 & NO & 1.295 & NO & 0.936 \\
C2 & $O$ & 0.470 & $O$ & 0.426 & NO & 0.872 & NO & 1.007 \\
C3 & $O$ & 0.676 & $O$ & 0.700 & NO & 0.796 & NO & 1.622 \\
C4 & $O$ & 0.521 & $O$ & 0.593 & $O$ & 0.740 & $O$ & 0.627 \\
\hline
\end{tabular}


groupings in the NGLS. This exposure then increased the interactivity between teachers and students, which would suggest a more dynamic learning setting, when compared against the traditional classroom layout.

\section{Effect of the Formal Learning Space on Students' Perceived Levels of Engagement}

The final research question of this study addressed how the change from the NGLS to the traditional classroom affected student engagement in their learning. The combined quantitative approach of visual analysis and Cohen's $d$ effect sizes resulted in a statistically significant difference in seven out of the eight questions (Table 4).

Table 4. Summary table of the changes in student perception of changes in their levels of engagement in mode 3 space compared to mode 1 (withdrawal)

\begin{tabular}{lcccc}
\hline Class & \multicolumn{2}{c}{ Increased interest in learning $\left(C^{1}\right)$} & Preferred space to learn $\left(C^{2}\right)$ \\
\cline { 2 - 5 } & $\begin{array}{c}\text { Visual } \\
\text { analysis }\end{array}$ & $\begin{array}{c}\text { Cohen's } d \\
\text { effect size }\end{array}$ & $\begin{array}{c}\text { Visual } \\
\text { analysis }\end{array}$ & $\begin{array}{c}\text { Cohen's d } \\
\text { effect size }\end{array}$ \\
\hline $\mathrm{C} 1$ & NO & 1.776 & NO & 2.259 \\
$\mathrm{C} 2$ & $N O$ & 1.226 & NO & 1.713 \\
$\mathrm{C} 3$ & $N O$ & 1.949 & NO & 1.042 \\
$\mathrm{C} 4$ & $N O$ & 1.145 & $O$ & 0.867 \\
\hline
\end{tabular}

All four classes returned a statistically significant difference in how the NGLS influenced their 'interest in learning' (C). ${ }^{1}$ Of note, the effect sizes were either large ( $\mathrm{C} 2$ or $\mathrm{C} 4)$ or very large ( $\mathrm{C} 1$ and $\mathrm{C} 3)$. An exemplar of a very large effect size $(d=1.949)$ that was observed for Class $\mathrm{C} 3$ corroborated by visual analysis is provided in Figure 3. The change in level between the NGLS and the traditional classroom during the withdrawal period is both significant and stable.

The change from an NGLS to a traditional classroom had a similar statistically significant effect on where students 'preferred to learn'. The aim of this question $\left(\mathrm{C}^{2}\right)$ was to ascertain if the students' emotional engagement was associated with different learning spaces. Three of the classes $(\mathrm{C} 1, \mathrm{C} 2$ and $\mathrm{C} 3)$ strongly indicated that the NGLS was statistically their preferred space to learn. All three effect sizes were in excess of one, with classes $\mathrm{C} 1(d=2.259)$ and $\mathrm{C} 2(d=1.713)$ returning a very large effect size. Figure 4 provides a visual representation of Class C2's responses to question $\mathrm{C}^{2}$ across the baseline/NGLS/withdrawal periods. Of note is the substantially higher and very small variability observed during the NGLS period, compared to the baseline/withdrawal periods. It is hypothesised that if students have a stronger emotional engagement to a particular classroom space that they will have greater interest and intrinsic motivation to learn. 


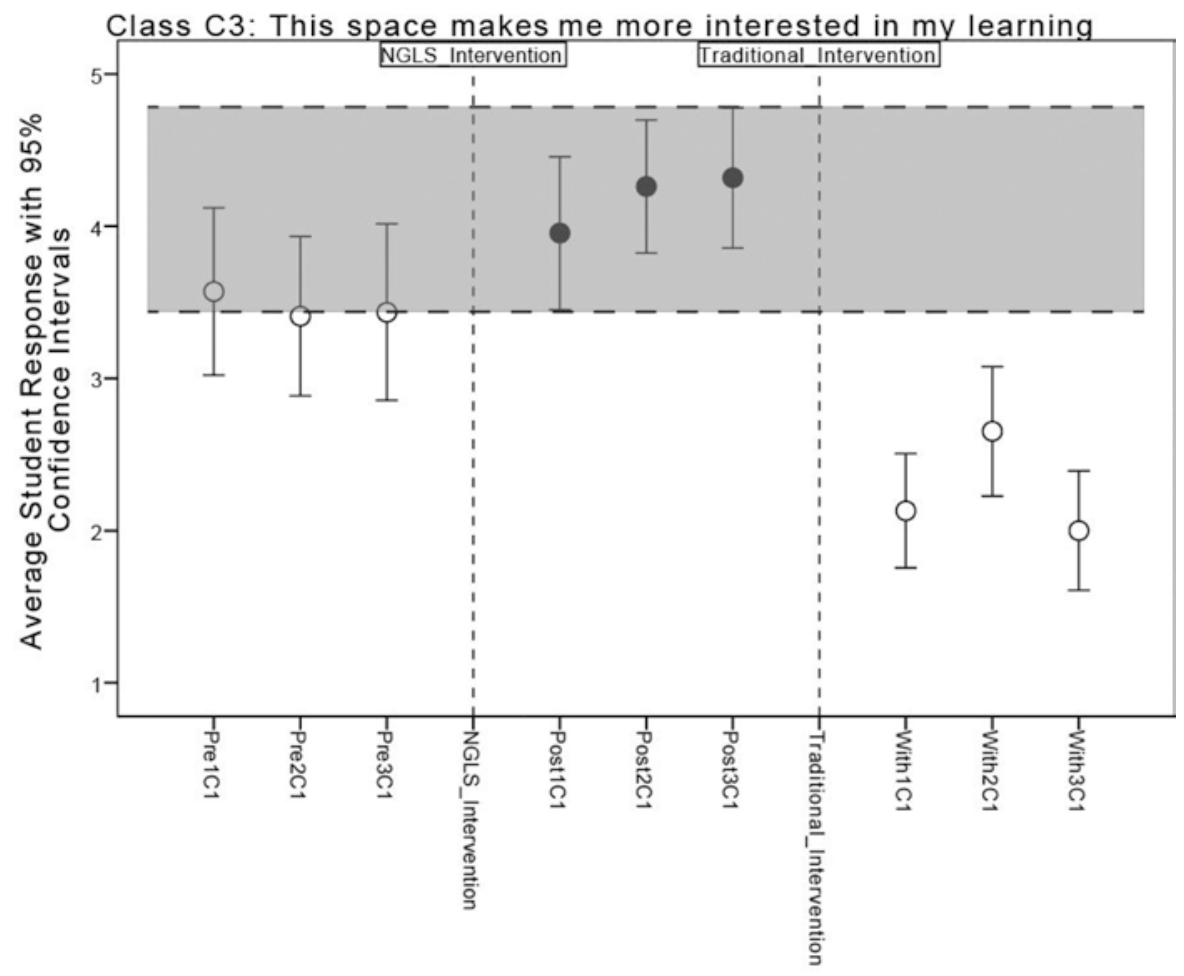

Figure 3. The statistically significant change in C3 class's interest in their learning in the NGLS compared to the traditional (withdrawal) classroom

\section{CONCLUSION}

There is growing attention in the literature on the integration and use of digital technology and contemporary learning spaces, and the subsequent effect on teaching and learning. Even though there has been significant funding and human resources directed to these areas, there has been limited empirical evaluation of their collective causal effect on school-age students.

The aim of this study was two-fold. Firstly, it sought to test, refine and validate the methodology of the Byers et al. (2014) and Byers and Imms (2014) studies through its replication in a primary years setting. Secondly, it attempted to build upon limited empirical evidence reported in these earlier studies. The overall aim was to increase knowledge about the causal effect of NGLS on teaching and learning. Collectively this study, along with the notable work of Brooks $(2011,2012)$, has established valid methods for measuring the impact of learning spaces. In the process, they provide empirical evidence informing discussion about the nature of this impact. 


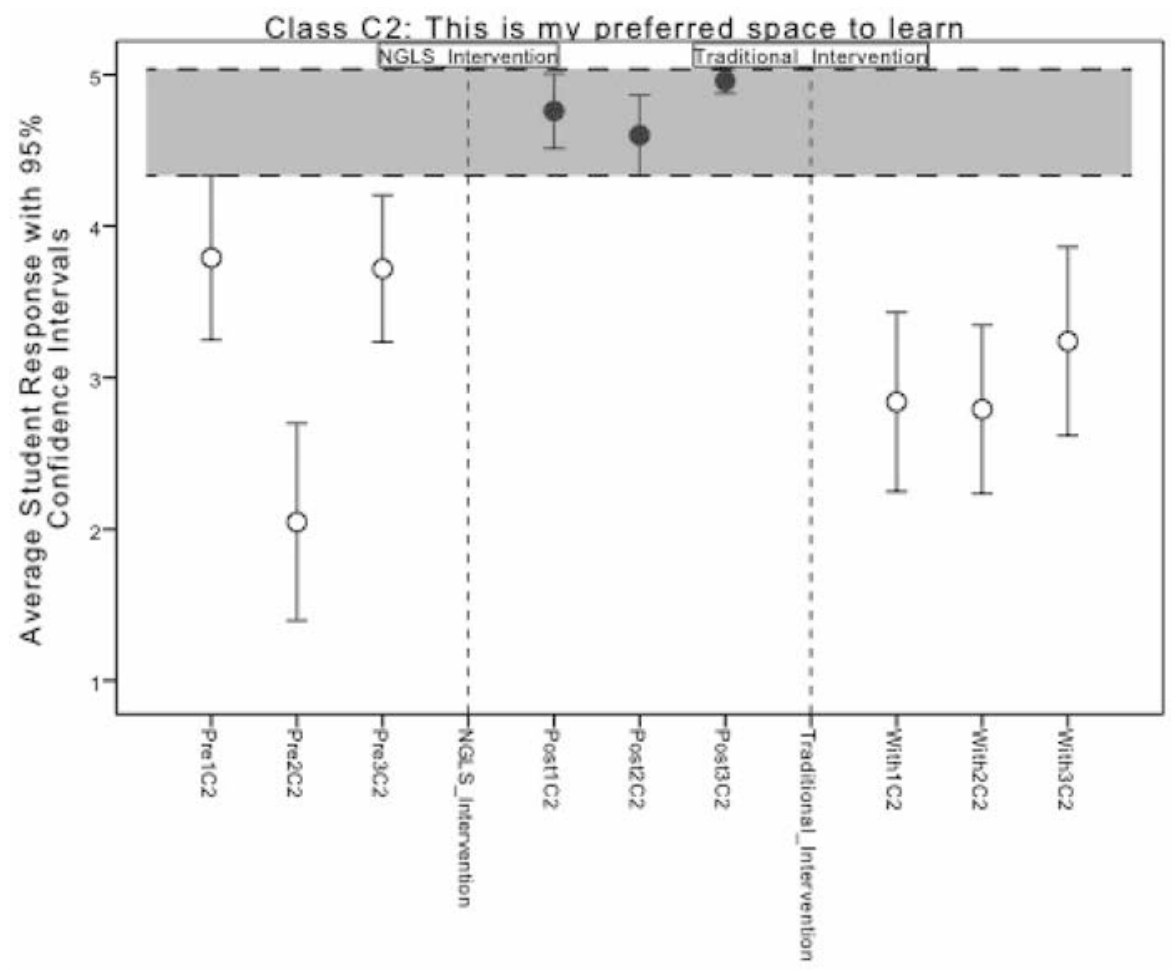

Figure 4. The statistically significant change in C2 class's preferred space to learning in the NGLS compared to the traditional (baseline/withdrawal) classroom

The methodology, a synthesised quasi-experimental and SSRD, has been shown to work in both a primary and middle years settings. This synthesised approach has demonstrated its robustness and reliability through its replication of confounding variable control, instrumentation and data analysis techniques to a different context. This assertion is justified through similar a priori power and Cronbach's alpha analysis and a high retention rate that occurred in the Byers et al. (2014) and Byers and Imms (2014) studies.

The empirical findings presented here have added to the evidence that suggests causal links between NGLS and positive effects on teaching and learning. The analysis of the student surveys across the baseline/intervention/withdrawal periods suggested that alignment between the affordances of digital technology and the physical classroom environment has a positive influence and effectiveness is improved. These findings are comparable to those derived in the Byers and Imms (2014) study. Collectively this quantitative evidence does add weight to assertions 
made by Fisher (2010) and Lippman (2010) that 'alignment' between space and technology can result in a positive pedagogical effect.

In terms of pedagogy, the change from traditional to NGLS did have a demonstrable positive effect on perceptions of student learning experiences. The results suggested that the participating students felt they were exposed to more collaborative and interactive learning experiences in the flexible and dynamic NGLS, when compared to the more rigid and static traditional classroom.

This would suggest, as identified in the Byers et al. (2014) study, that when teachers are provided with the affordance of an NGLS, they are often able to create different, and more active, learning experiences for their students. Not surprisingly these different learning experiences in the NGLS had a corresponding and positive effect on student engagement levels.

The move to the NGLS was associated with significant improvements in students' perceived levels of engagement. Students indicated that they were more interested in their learning in a NGLS. Also, that the NGLS was their preferred space to learn. It is hypothesised that these improvements in student 'emotional engagement' in their learning would have an influence on student learning and thereby learning outcomes.

\section{ACKNOWLEDGEMENTS}

The authors wish to acknowledge the classroom teachers who were involved in this study, without whose support this study would not have been able to occur. The authors also acknowledge the support of the Anglican Church Grammar School and the University of Melbourne's LEaRN group, which financially supported the study.

\section{NOTE}

1 The ABA Design is a three phase design consisting of a no-intervention baseline phase (A), an intervention phase (B), and a no-intervention withdrawal phase (A).

\section{REFERENCES}

Baguley, T. (2009). Standardized or simple effect size: What should be reported? British Journal of Psychology, 100, 603-617. doi:10.1348/000712608X377117

Bautista, G., \& Borges, F. (2013). Smart classrooms: Innovation in formal learning spaces to transform learning experiences. Bulletin of the IEEE Technical Committeee on Learning Technology, 15(3), 18-21. Retrieved from http://lttfieee.org/

Bebell, D., \& Kay, R. (2010). One to one computing: A summary of the quantitative results from the Berkshire wireless learning initiative. The Journal of Technology, Learning and Assessment, 9(2).

Beeson, P. M., \& Robey, R. R. (2006). Evaluating single-subject treatment research: Lessons learned from the aphasia literature. Neuropsychology Review, 16(4), 161-169. doi:10.1007/s11065-006-9013-7

Blackmore, J., Bateman, D., O'Mara, J., \& Loughlin, J. (2011). Research into the connection between built learning spaces and student outcomes: Literature review. Melbourne, Australia: Victorian Department of Education and Early Childhood Development Retrieved from http://www.eduweb.vic.gov.au/ edulibrary/public/publ/research/publ/blackmore_learning_spaces.pdf 


\section{EVALUATING THE CHANGE IN SPACE}

Blin, F., \& Munro, M. (2008). Why hasn't technology disrupted academics' teaching practices? Understanding resistance to change through the lens of activity theory. Computers and Education, 50(2), 475-490. doi:10.1016/j.compedu.2007.09.017

Bobrovitz, C. D., \& Ottenbacher, K. J. (1998). Comparison of visual inspection and statistical analysis of single-subject data in rehabilitation research. American Journal of Physical Medicine and Rehabilitation, 77(2), 94-102.

Bocconi, S., Kampylis, P. G., \& Punie, Y. (2012). Innovating learning: Key elements for developing creative classrooms in Europe. Luxembourg, Europe: Joint Research Centre for the European Commission.

Brooks, D. C. (2012). Space and consequences: The impact of different formal learning spaces on instructor and student behavior. Journal of Learning Spaces, 1(2), 1-10. doi:http://z.umn.edu/jols

Buchanan, R. (2011). Paradox, promise and public pedagogy: Implications of the federal government's digital education revolution. Australian Journal of Teacher Education, 36(2), 6. doi:10.14221/ ajte. $2011 \mathrm{v} 36 \mathrm{n} 2.6$

Burke, C., \& Grosvenor, I. (2008). School. London, England: Reaktion.

Byers, T., \& Imms, W. (2014). Making the space for space: The effect of the classroom layout on teacher and student usage and perception of one-to-one technology. Paper presented at the Conference Proceedings of the Australian Computers in Education Conference 2014.

Byers, T., Imms, W., \& Hartnell-Young, E. (2014). Making the case for space: The effect of learning spaces on teaching and learning. Curriculum and Teaching, 29(1), 5-19. doi:10.7459/ct/29.1.02

Byiers, B. J., Reichle, J., \& Symons, F. J. (2012). Single-subject experimental design for evidencebased practice. American Journal of Speech-Language Pathology, 21(4), 397-414. doi:10.1044/ 1058-0360(2012/11-0036)

Casey, L. B., Meindl, J. N., Frame, K., Elswick, S., Hayes, J., \& Wyatt, J. (2012). Current trends in education: How single-subject research can help middle and high school educators keep up with the zeitgeist. Clearing House: A Journal of Educational Strategies, Issues and Ideas, 85(3), 109-116.

Chan, T.-W., Roschelle, J., His, S., Kinshuk, S., Sharples, M., Brown, T., ... Norris, C. (2006). One-toone technology-enhanced learning: An opportunity for global research collaboration. Research and Practice in Technology Enhanced Learning, 1(1), 3-29.

Chandler, W. L. (2009). "A" teacher space or a learner place? Reconsidering the classroom environment. International Journal of Learning, 16(9), 261-267. Retrieved from http://www.Learning-Journal.com

Clegg, S. (2005). Evidence-based practice in educational research: A critical realist critique of systematic review. British Journal of Sociology of Education, 26(3), 415-428. doi:10.1080/01425690500128932

Cleveland, B. W. (2009). Engaging spaces: An investigation into middle school educational opportunities provided by innovative built environments: A new approach to understanding the relationship between learning and space. International Journal of Learning, 16(5), 385-397. Retrieved from http://www.Learning-Journal.com

Cleveland, B. W. (2011). Engaging spaces: Innovative learning environments, pedagogies and student engagement in the middle years of school (Doctor of Philosophy). University of Melbourne, Melbourne, Australia.

Cohen, J. (1998). Statistical power analysis for the behavioral sciences (2nd ed.). New Jersey, NJ: Erlbaum.

Condie, R., \& Munro, R. (2007). The impact of ICT in schools - A landscape review. Retrieved from http://dera.ioe.ac.uk/1627/1/becta_2007_landscapeimpactreview_report.pdf

Coryn, C. L. S., Schröter, D. C., \& Hanssen, C. E. (2009). Adding a time-series design element to the success case method to improve methodological rigor an application for nonprofit program evaluation. American Journal of Evaluation, 30(1), 80-92. doi:10.1177/1098214008326557

Cuban, L. (2001). Oversold and underused: Computers in the classroom Cambridge, MA: Harvard University Press.

Donovan, L., Green, T., \& Hartley, K. (2010). An examination of one-to-one computing in the middle school: Does increased access bring about increased student engagement? Journal of Educational Computing Research, 42(4), 423-441. 


\section{T. BYERS \& W. IMMS}

Faul, F., Erdfelder, E., Lang, A.-G., \& Buchner, A. (2007). G*power 3: A flexible statistical power analysis program for the social, behavioral, and biomedical sciences. Behavior Research Methods, $39(2), 175-191$.

Fisher, K. D. (2004). Revoicing classrooms: A spatial manifesto. Forum, 46(1), 36-38.

Fisher, K. D. (2010). Technology-enabled active learning environments: An appraisal. CELE Exchange. Centre for Effective Learning Environments, 2010(6-10), 1-8.

Fried, C. B. (2008). In-class laptop use and its effects on student learning. Computers and Education, 50(3), 906-914. doi:10.1016/j.compedu.2006.09.006

Fullan, M., Hill, P., \& Crevola, C. (2007). Breakthrough. Victoria, Australia: Hawker Brownlow Education.

Gliem, J. A., \& Gliem, R. R. (2003). Calculating, interpreting, and reporting Cronbach's alpha reliability coefficient for likert-type scales. Paper presented at the Midwest Research-to-Practice Conference in Adult, Continuing, and Community Education, The Ohio State University, Columbus, $\mathrm{OH}$.

Hall-van den Elsen, C., \& Palaskas, T. (2014). Transition to next generation learning spaces. In K. Fraser (Ed.), The future of learning and teaching in next generation learning spaces (Vol. 12, pp. 199-218). England: Emerald Group Publishing Limited.

Harris, A. D., McGregor, J. C., Perencevich, E. N., Furuno, J. P., Zhu, J., Peterson, D. E., \& Finkelstein, J. (2006). The use and interpretation of quasi-experimental studies in medical informatics. Journal of the American Medical Informatics Association, 13(1), 16-23. doi:10.1197/jamia.M1749

Hermans, R., Tondeur, J., van Braak, J., \& Valcke, M. (2008). The impact of primary school teachers' educational beliefs on the classroom use of computers. Computers and Education, 51(4), 1499-1509.

Higgins, S., Hall, E., Wall, K., Woolner, P., \& McCaughey, C. (2005). The impact of school environments: A literature review. Newcastle, England: Center for Learning and Teaching, School of Education, Communication and Language Science, University of Newcastle.

Higgins, S., Beauchamp, G., \& Miller, D. (2007). Reviewing the literature on interactive whiteboards. Learning, Media and Technology, 32(3), 213-225. doi:10.1080/17439880701511040

Higgins, S., Xiao, Z., \& Katsipataki, M. (2012). The impact of digital technology on learning: A summary for the education endowment foundation. Retrieved November 27, 2013, from http://educationendowmentfoundation.org.uk/uploads/pdf/The_Impact_of_Digital_Technologies on Learning \%282012\%29.pdf

Hildebrand, G. M. (1999). Contesting learning models. Paper presented at the Australian Association for Research in Education and New Zealand Association for Research in Education Conference, Melbourne, Australia.

Horner, R. H., Carr, E. G., Halle, J., McGee, G., Odom, S., \& Wolery, M. (2005). The use of singlesubject research to identify evidence-based practice in special education. Exceptional Children, 71(2), $165-179$.

Horner, R. H., Swaminathan, H. S., \& George, S. K. (2012). Considerations for the systematic analysis and use of single-case research. Education and Treatment of Children, 35(2), 269.

Hughes, J. (2005). The role of teacher knowledge and learning experiences in forming technologyintegrated pedagogy. Journal of Technology and Teacher Education, 13(2), 277-302. Retrieved from http://www.editlib.org

Hughes, J., Thomas, R., \& Scharber, C. (2006). Assessing technology integration: The RAT-Replacement, amplification, and transformation - Framework. In C. Crawford, R. Carlsen, K. McFerrin, J. Price, R. Weber, \& D. Willis (Eds.), Proceedings of Society for Information Technology and Teacher Education International Conference 2006 (pp. 1616-1620). Chesapeake, VA: Association for the Advancement of Computing in Education (AACE)

Hur, J. W., \& Oh, J. (2012). Learning, engagement, and technology: Middle school students' three-year experience in pervasive technology environments in South Korea. Journal of Educational Computing Research, 46(3), 295-312. doi:10.2190/EC.46.3.e

Jacklin, H. (2000). Locating pedagogy. Paper presented at the British Sociological Association Annual Conference, York, England. 
Jenson, W. R., Clark, E., Kircher, J. C., \& Kristjansson, S. D. (2007). Statistical reform: Evidence-based practice, meta-analyses, and single subject designs. Psychology in the Schools, 44(5), 483-493.

Jessop, T., Gubby, L., \& Smith, A. (2012). Space frontiers for new pedagogies: A tale of constraints and possibilities. Studies in Higher Education, 37(2), 189-202. doi:10.1080/03075079.2010.503270

Johnston, M. V., Ottenbacher, K. J., \& Reichardt, C. S. (1995). Strong quasi-experimental designs for research on the effectiveness of rehabilitation. American Journal of Physical Medicine and Rehabilitation, 74, 383-392.

Kinugasa, T., Cerin, E., \& Hooper, S. (2004). Single-subject research designs and data analyses for assessing elite athletes' conditioning. Sports Medicine, 34(15), 1035-1050.

Kromrey, J. D., \& Foster-Johnson, L. (1996). Determining the efficacy of intervention: The use of effect sizes for data analysis in single-subject research. The Journal of Experimental Education, 65(1), 73-93.

Lin, J. M. C., Wang, P. Y., \& Lin, I. (2012). Pedagogy* technology: A two-dimensional model for teachers' ICT integration. British Journal of Educational Technology, 43(1), 97-108.

Lippman, P. C. (2010). Can the physical environment have an impact on the learning environment? CELE Exchange, Centre for Effective Learning Environments, 2010(11-14), 1-5.

Lippman, P. C. (2013). Designing collaborative spaces for schools: Part 1. The Journal, January. Retrieved from http://thejournal.com/articles/2013/02/13/designing-collaborative-spaces-for-schools.aspx

Magee, C. M. (2009). A phenomenological, hermeneutic case study of two studio learning environments: Reggio Emilia pre-school atelier and MIT teal freshmen studio physics (Doctor of Education). The George Washington University, Washington, DC. Retrieved from EBSCOhost psyh database website: https://ezp.lib.unimelb.edu.au/login?url=https://search.ebscohost.com/ login.aspx?direct=true \&db=psyh\&AN=2009-99231-304\&scope $=$ site

Matzen, N. J., \& Edmunds, J. A. (2007). Technology as a catalyst for change: The role of professional development. Journal of Research on Technology in Education, 39(4), 417-430.

McCarter, S., \& Woolner, P. (2011). How listening to student voice can enable teachers to reflect on and adjust their use of physical space. Educational and Child Psychology, 28(1), 20-32.

McGregor, J. (2004). Space, power and the classroom. Forum, 46(1), 13-18.

Miller-Cochran, S., \& Gierdowski, D. (2013). Making peace with the rising costs of writing technologies: Flexible classroom design as a sustainable solution. Computers and Composition, 30(1), 50-60. doi:10.1016/j.compcom.2012.12.002

Mishra, P., \& Koehler, M. J. (2006). Technological pedagogical content knowledge: A framework for teacher knowledge. Teachers College Record, 108(6), 1017-1054.

Mitchell, M. L., \& Jolley, J. M. (2012). Research design explained (8th ed.). Belmont, CA: Wadsworth Cengage Learning.

Monahan, T. (2002). Flexible space and built pedagogy: Emerging IT embodiments. Inventio, 4(1), 1-19. Retrieved from http://www.torinmonahan.com/papers/Inventio.html

Mouza, C., \& Lavigne, N. C. (2013). Introduction to emerging technologies for the classroom: A learning sciences perspective. In C. Mouza \& N. C. Lavigne (Eds.), Emerging technologies for the classroom: A learning sciences perspective (pp. 1-12). New York, NY: Springer.

Perone, M. (1999). Statistical inference in behavior analysis: Experimental control is better. The Behavior Analyst, 22, 109-116.

Peugh, J. L., \& Enders, C. K. (2004). Missing data in educational research: A review of reporting practices and suggestions for improvement. Review of Educational Research, 74(4), 525-556.

Pintrich, P. R., \& de Groot, E. V. (1990). Motivational and self-regulated learning components of classroom academic performance. Journal of Educational Psychology, 82(1), 33-40.

Prieto, L. P., Dlab, M. H., Gutiérrez, I., Abdulwahed, M., \& Balid, W. (2011). Orchestrating technology enhanced learning: a literature review and a conceptual framework. International Journal of Technology Enhanced Learning, 3(6), 583-598.

Radcliffe, D., Wilson, H., Powell, D., \& Tibbetts, B. (2008). Designing next generation places of learning: Collaboration at the pedagogy-space-technology nexus. Brisbane, Australia: The University of Queensland. 


\section{T. BYERS \& W. IMMS}

Rassafiani, M., \& Sahaf, R. (2010). Single case experimental design: An overview. International Journal of Therapy and Rehabilitation, 17(6), 285-289.

Reynard, R. (2009, April). Designing learning spaces for instruction, not control. Campus Technology. Retrieved from http://campustechnology.com/articles/2009/04/29/designing-learning-spaces-forinstruction-not-control.aspx

Richards, C. (2006). Towards an integrated framework for designing effective ICT-supported learning environments: The challenge to better link technology and pedagogy. Technology, Pedagogy and Education, 15(2), 239-255. doi:10.1080/14759390600769771

Robson, C. (2011). Real world research: A resource for social scientists and practitioner-researchers (3rd ed.). Chichester \& Hoboken, England: Wiley-Blackwell.

Rosen, Y., \& Beck-Hill, D. (2012). Intertwining digital content and a one-to-one laptop environment in teaching and learning: Lessons from the time to know program. Journal of Research on Technology in Education, 44(3), 225.

Ross, S. M., Morrison, G. R., \& Lowther, D. L. (2010). Educational technology research past and present: Balancing rigor and relevance to impact school learning. Contemporary Educational Technology, $1(1), 17-35$.

Shadish, W. R., \& Cook, T. D. (1999). Comment-design rules: More steps toward a complete theory of quasi-experimentation. Statistical Science, 14(3), 294-300. doi:10.2307/2676764

Swan, K., van'T Hooft, M., Kratcoski, A., \& Schenker, J. (2007). Ubiquitous computing and changing pedagogical possibilities: Representations, conceptualizations and uses of knowledge. Journal of Educational Computing Research, 36(4), 481-515.

Tamim, R. M., Lowerison, G., Schmid, R. F., Bernard, R. M., \& Abrami, P. C. (2011). A multi-year investigation of the relationship between pedagogy, computer use and course effectiveness in postsecondary education. Journal of Computing in Higher Education, 23(1), 1-14. doi:10.1007/ s12528-010-9041-4

Thomas, D., \& Brown, J. S. (2011). A new culture of learning: Cultivating the imagination for a world of constant change. Lexington, KY: CreateSpace.

Upitis, R. (2004). School architecture and complexity. Complicity: An International Journal of Complexity and Education, 1(1), 19-38. Retrieved from www.complexityandeducation.ca

Upitis, R. (2009). Complexity and design: How school architecture influences learning. Design Principles and Practices: An International Journal, 3(2), 1-14.

Vickers, A. (2003). How many repeated measures in repeated measures designs? Statistical issues for comparative trials. BMC Medical Research Methodology, 3(1), 22.

West, S. G., \& Thoemmes, F. (2010). Campbell's and Rubin's perspectives on causal inference. Psychological Methods, 15(1), 18-37. doi:10.1037/a0015917

Wilks, S. (2009). Observing the transformation of pedagogies and spaces. Critical and Creative Thinking, 17(2), 29-57.

Wood, R., \& Ashfield, J. (2008). The use of the interactive whiteboard for creative teaching and learning in literacy and mathematics: A case study. British Journal of Educational Technology, 39(1), 84-96.

Zandvliet, D. B., \& Fraser, B. J. (2004). Learning environments in information and communications technology classrooms. Technology, Pedagogy and Education, 13(1), 97-123. doi:10.1080/ 14759390400200175

Zucker, A. A. (2007). A framework for studying 1:1 computing initiatives. In M. van’T Hooft \& K. Swan (Eds.), Ubiquitous computing in education: Invisible technology, visible impact (pp. 147-166). Mahwah, NJ: Erlbaum.

\section{Terry Byers}

University of Melbourne

Wesley Imms

University of Melbourne 